\title{
DOES STRONG FACULTY SUPPORT EQUAL CONSISTENT COURSE COMPLETION?: IT HAS FOR DALLAS BAPTIST UNIVERSITY
}

\author{
Kaye Shelton \\ Dallas Baptist University
}

\section{INTRODUCTION TO DALLAS BAPTIST UNIVERSITY}

Dallas Baptist University (DBU) is a private, Christian, liberal arts institution located in the DFW Metroplex. Just over 5,200 students, DBU provides both traditional undergraduate, adult and graduate degrees with the enrollment almost equally divided between the three student groups. Today, DBU offers 34 degree programs fully online maintains a course completion rate of 92-93\% each semester with almost 2,000 students taking online classes. Because of its continued success and dedication to quality course development, the DBU online education department has become a model for several other higher education institutions.

\section{INSTITUTIONAL COMMITMENT}

Because DBU is a student-centered institution that tries to listen to the needs of its students, in 1998, DBU began offering online classes. Then, very few private Christian institutions had ventured into delivering online education. DBU had a small distance education program with a few audio and video courses and several off-site classrooms with corporations that included some video conferencing which was supplied by the corporation.

Because of its strong adult degree completion program, the university president, Dr. Gary Cook, recommended that the university begin developing and offering online classes and full degree programs. The university quickly shifted into planning and developing policies while many other institutions refused to see the relevance. It meant a strong paradigm shift for the university, but slowly and effectively, the program moved forward. Pretty quickly, the other methods of distance education faded away because the students liked the flexibility that online classes provided.

\section{FACULTY DEVELOPMENT AND SUPPORT}

Even though the campus culture is used to embracing change, this was still a huge paradigm shift for faculty as it is with most institutions. Recognizing that faculty involvement would be the strength of the program, a faculty support system was designed to encourage faculty buy-in and support for online classes. DBU's philosophy is that faculty are discipline experts and should not have to become web designers or technical gurus. They should be able to concentrate on teaching and engaging their students.

So from the very beginning, faculty received compensation for developing course materials and had access to technical and course design support. DBU compensates faculty course developers either one course overload or one course release for course development. Because we believe instructor involvement is critical, all online classes are limited to 22 enrollments as the research suggests a range of 12-25 students is the most any one online instructor can effectively engage. The initial training for faculty 
developing online courses includes instructional design strategy, information on copyright for online materials (the TEACH Act) as well as an orientation to how the process works for course development. At this time, the faculty member is introduced to the Profhelp team, a team of course developers that will support the instructor throughout the course development process as well as teaching the class.

After receiving some information on how effectively to use Blackboard, the online courseware management system, the instructor works with the Profhelp team to design digital course content. The instructor can send a simple Word document with lecture material, assignment information and discussion questions, and a Profhelp team member applies instructionally design, adds graphical support and learning objects and places it within the appropriate course shell within Blackboard. Once the instructor approves the design, the Prohelp team then helps to facilitate the proofing process.

All course materials are proofed by at least one or two instructor(s) in the discipline, the college dean, a research analyst and the Provost. While rigorous, this provides a quality assurance process for the course materials as these course become master content courses for others instructors to use when teaching online. Each course is reviewed for quality content and student engagement strategy. Once the instructor approves suggested edits, the Profhelp team member makes the edits in the course material as well as loads the exam and quiz questions for each course.

Once the course is fully developed, the final training for the instructor is with the dean of online education for ePedagogy. Instructors that have not developed an online course but may be teaching online for the first time, also attend this important training. This training provides insight into the differences between teaching in the traditional classroom and online and also provides techniques for successfully creating an online learning community and engaging students. Tips and tricks for managing workload are also covered as well as explaining the ongoing quality assurance process for the course. Each semester, online courses have a team member assigned to make sure all links are working, dates are set correctly, and exams and quizzes are functioning.

\section{SCALE}

Today, DBU's online education program has seven full time course developers and four part-time, who work from home on the quality assurance process. About $70 \%$ of the full time faculty teach online and $42.7 \%$ of the adjuncts. A benefit of wide faculty participation is that Dallas Baptist University will be in a good position to continue courses online should an event disrupt on-campus attendance.

In summer 2009, 51\% of the students took online courses, constituting $39.5 \%$ of the total hours. .Last spring, the split was about 20\% traditional and the rest adult and graduate. Up until the fall 2009 semester, traditional students were limited from taking online classes in the fall and spring semesters but could take unlimited in the summer and winter. It will be interesting to see how the new policy affects overall course completion rates in traditional courses. Appendix A is a history of online course completion rates from Fall 1998 through Spring 2009.

\section{RECOGNITION}

The excellent faculty support provided by this department has resulted in two exemplary course awards and being part of a benchmarking project. In 2006, the DBU Online Education program entered into a self-audit to benchmark against other quality online programs. This opportunity was requested by the AHEC-Alliance for Higher Education Competitiveness. The graphic below demonstrates the six key 
factors audited in the process. DBU Online Education was ranked as a Best Practice Leader as demonstrated by the following graphic.

\section{Success Factors Radar}

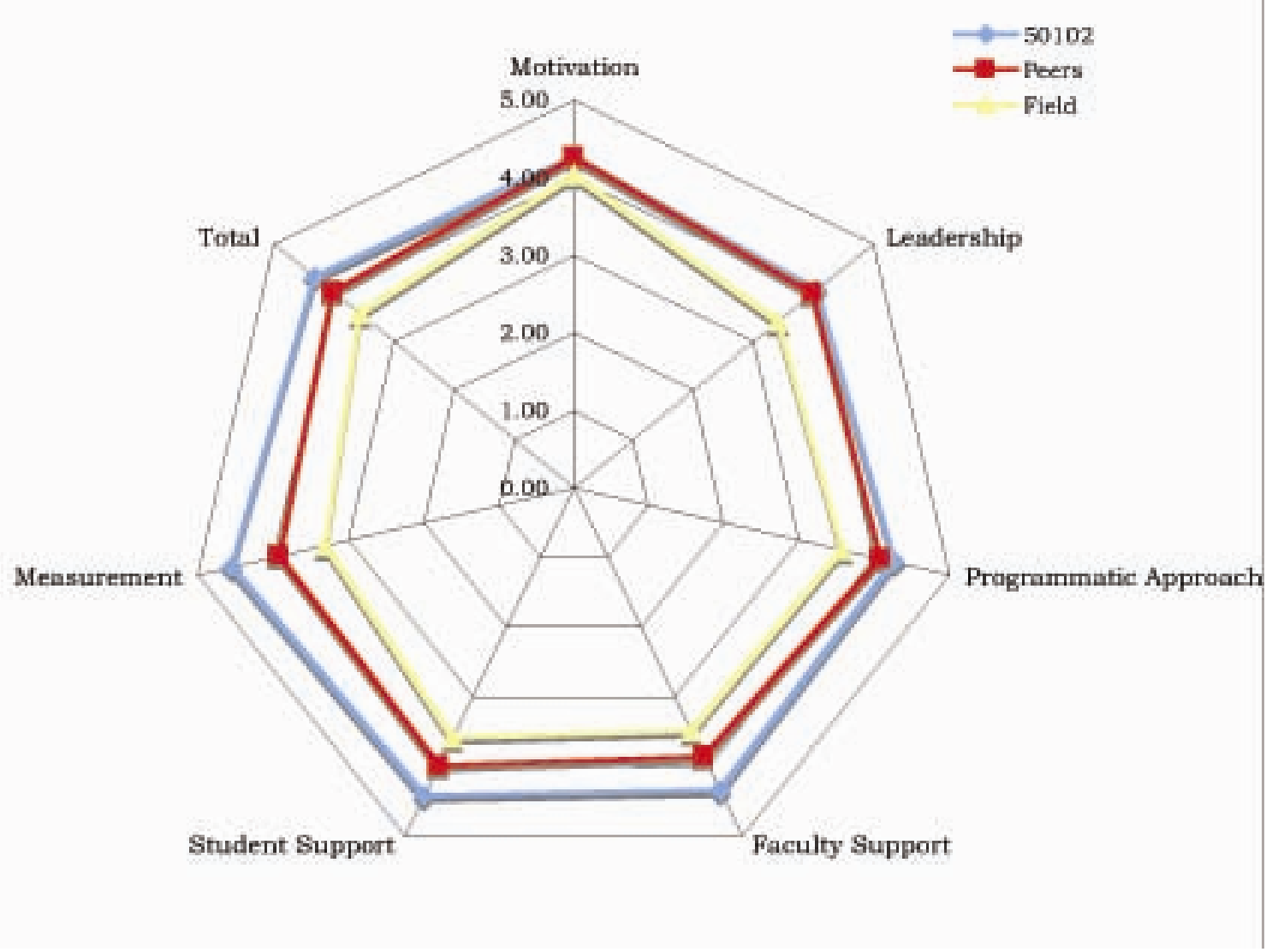

Figure 1. Success Factors: Motivation, Leadership, Programmatic Approach, Student Support and Measurement

Additionally, DBU was awarded the Blackboard Exemplary Course award in 2005 and the Instructional Technology Council's eLearning course award in 2006. However, the greatest measure of faculty support is the consistent course completion rate that DBU maintains. The table below shows both individual semester and cumulative rates. This strong completion rate can be attributed to the amount of support faculty receive and their ability to engage students in the online classroom.

\section{ABOUT THE AUTHOR}

Kaye Shelton is the dean of online education at Dallas Baptist University, whose online program now offers 34 degrees fully online and maintains a 92\% student course completion rate. Under her leadership, the DBU Online Ed program has won multiple awards in exemplary online course development. She is a certified online instructor and also practices as an online education consultant and has served as an advisor regarding online education programs for many peer institutions. Research interests include faculty support for online teaching and quality in online programs. 


\section{APPENDIX A}

Fall 1998

Spring 1999

Summer 1999

Fall 1999

Spring 2000

Summer 2000

Fall 2000

Spring 2001

Summer 2001

Fall 2001

Winter 2002

Spring 2002

Summer 2002

Fall 2002

Winter 2003

Spring 2003

Summer 2003

Fall 2003

Winter 2004

Spring 2004

Summer 2004

Fall 2004

Winter 2005

Spring 2005

Summer 2005

Fall 2005

Winter 2006

Spring 2006

Summer 2006

Fall 2006

Winter 2007

Spring 2007

Summer 2007

Fall 2007

Winter 2008

Spring 2008

Summer 2008

Fall 2008

Winter 2009

Spring 2009
Total Completion Rate \%-age

$100.00 \%$

$96.55 \%$

$89.81 \%$

$96.64 \%$

$97.14 \%$

$90.69 \%$

$93.39 \%$

$92.35 \%$

$92.82 \%$

$91.85 \%$

$97.50 \%$

$91.97 \%$

93.05\%

$92.60 \%$

$94.39 \%$

$92.31 \%$

$93.82 \%$

$92.51 \%$

$94.52 \%$

$93.35 \%$

$96.00 \%$

$91.54 \%$

$97.72 \%$

$94.39 \%$

$94.28 \%$

$92.52 \%$

$95.96 \%$

$92.82 \%$

$91.72 \%$

93.99\%

$96.00 \%$

$91.76 \%$

$94.00 \%$

$91.39 \%$

$93.53 \%$

$92.68 \%$

$91.95 \%$

$93.09 \%$

$95.27 \%$

$93.49 \%$
Cumulative Completion Rate \%-age

$100.00 \%$

$97.10 \%$

$92.66 \%$

$94.94 \%$

95.95\%

94.22\%

93.93\%

93.49\%

93.36\%

92.98\%

93.24\%

92.98\%

92.99\%

92.93\%

93.00\%

92.91\%

$92.41 \%$

92.43\%

$92.49 \%$

92.59\%

92.86\%

$92.72 \%$

92.85\%

92.98\%

93.07\%

93.02\%

93.08\%

93.06\%

92.98\%

93.06\%

$93.11 \%$

93.01\%

93.05\%

92.92\%

92.92\%

$92.90 \%$

92.86\%

92.88\%

92.92\%

92.96\% 